\title{
Supply chain coordination of altruism in information sharing
}

\author{
Qing Dong ${ }^{a^{*}}$, Xiangqing Liang ${ }^{b}$, Gengxin Dai $^{a}$ \\ ${ }^{a}$ Qing Dao University, Qing Dao, China \\ ${ }^{\mathrm{b}}$ Nan Jing Audit College, Nan Jing, China \\ *Corresponding author: Qing Dong, Ddq0502@foxmail.com
}

\begin{abstract}
The altruistic preference of the decision maker is introduced into the supply chain model, and the supply chain of retailers and manufacturers is established under the condition of information sharing. In a state of information sharing, the introduction of altruism can better analyze the operation patterns of manufacturers and retailers in the market. By establishing the model, draw the conclusion: the manufacturers are more willing in the expected demand sufficiently large environment and altruistic retailers, but most are not willing with self interested retailers in the expected demand, which is not abundant in cooperation. At the same time, the income of the manufacturer will increase with the growth of retailers altruistic in the expected demand of environment. In the same way, retailers are more willing to cooperate with altruistic manufacturers when the supply chain is expected to be in great demand.
\end{abstract}

Keywords: altruistic strength; information sharing; demand expected value; supply chain coordination

\section{Introduction}

Since the 1990s, the homogeneity of products and services, business across the region, the operating costs of pressure and the diversification of customer needs were becoming more and more obvious, enterprise competition has been transformed into competition between manufacturer and retailer. The high attention of the enterprise forms the synthesis of new management method and management theory that based on information technology to supply chain management ${ }^{1}$. In the supply chain, a business is a node, and the upstream and downstream enterprise is a relationship between demand and supply. It is significant to realize the control of the logistics and capital flow, to promote the operation of the whole supply chain performance, to improve customer service level of the enterprise and to reduce the total transaction cost, which depend on upstream enterprises getting real information about the 
market demand of downstream enterprises promptly and accurately, the supply chain information flowing within the smooth flow. Strengthening the cooperation of supply chain node enterprise and realizing the information sharing in supply chain and circulation, not only can increase the degree of customer orientation change of enterprises, but also make the enterprise in the changeable market that will enhance its flexibility and agility and obtain sustainable competitive advantage in the market ${ }^{[2]}$.Therefore, information flow and information sharing have become an indispensable part of supply chain management research and practice. The sharing of demand information has received extensive attention in both theory and practice. Generally, the closer the supply chain members are willing to the market, the more accurate demand can be predicted in market. If the downstream members of the supply chain are willing to share the projected demand information with their upstream partners, it will facilitate the upstream members to design more accurate production plans, thereby enhancing customer service levels ${ }^{2}$.

With the development of society, the supply chain has also been developed. In the past, the general consideration was based on rationality in the supply chain, and the supply chain did not consider the role of people, the core position of human beings is self-evident important in the supply chain system. In the past, the decision-maker was a perfect optimizer, and always made the best decision to maximize the benefits under the assumption of complete rationality. In fact, people are not completely rational, but limited rationality. People are not completely self-interested, but altruistic. These are theoretical bases. Simon ${ }^{3}$ believes that people are not completely rational in making decisions, but they are bounded rationality. Similarly, in the experimental and empirical studies, it is found that these theories contract supply chain coordination in many ways inconsistent with the actual situation. The reason is that the decision makers have social preferences in the supply chain, including fairness, reciprocity, altruism, regret avoidance, jealousy and other psychological preferences ${ }^{4}$. These attributes may have an impact on the decision maker, but the conditions and effects are different. For example, Pavlov ${ }^{5}$ and other studies have found that the actual ordering quantity of the retailer is less than the expected quantity of the supplier in the supply chain, because the fairness preference of the decision maker is not taken into account, which leads to the increase of the bullwhip effect. Based on this, the supply chain coordination theory begins to introduce the various behavioral psychology of human being, and adds behavioral preference into the coordination model of supply chain, so it aims to improve the explanatory power of economic phenomena and the guidance of economic behavior. Among them, altruistic attribute comes 
from ethics, which is a kind of welfare behavior and concerned not only about someone own interests, but also about the interests of the other. $\mathrm{Ge}^{6}$ and other suggest that retailers' altruistic preference behavior can mitigate the double marginal effect of supply chain. Tan Yanhong ${ }^{7}$ and other suggest that the supply chain decision-making model, found that suppliers can slow down the supply chain "double marginal effect", but can not be eliminated. Xu Minli and Shen Jiajing ${ }^{8}$ consider the relationship between manufacturer and supplier of quality investment revenue sharing about Asymmetric Information in the FS model under Fairness Preference. Lin Zhibing ${ }^{9}$ established a dual channel supply chain model based on altruistic attributes, discussed the impact of altruism on the dual channel supply chain, and found that altruism was beneficial to improve the efficiency of the dual channel.

At present, most researches only consider altruism attribute that is used in the supply chain and information sharing behaviour. However, in real life, all levels of supply chain not only show the behavior of profit, but also show altruistic behavior and the behavior of sharing information. Therefore, this article will introduce the supply chain information sharing model of altruism preference, which focuses on the analysis of the information sharing, and to find out how do the supply chain of altruistic develop and cooperate, making the model more realistic description of the economic environment.

\section{Model description and hypothesis}

On the basis of information sharing, establish a retailer and a supplier of altruistic preference supply chain. Supposed that the cost of supplier is $c$, the wholesale price of retailer from the supplier is $\omega$, and the selling price is $p$, then the demand of supplier is $q_{m}=\alpha+\theta_{m}-\lambda \omega$, and the demand of retailer is $q_{r}=\alpha+\theta_{r}-\lambda p$, where $\mathrm{y}$ and a are constant. For retailers to sell goods, $q$ is the uncertainty of commodity demand; $\theta$ is a stochastic variable, representing the uncertainty of the supply chain downstream market demand, and showing a normal distribution, that is, $\theta \square\left(0, \sigma_{0}^{2}\right)^{10}$ (Raju and Roy, 2002). Supply chain operations, manufacturers generally can not observe o, but retailers can master. In this way, the demand of manufacturer is

$$
\begin{aligned}
& q_{m}=\alpha+\theta_{m}+\lambda \omega \\
& \theta_{m} \square\left(0, \sigma_{m}^{2}\right)
\end{aligned}
$$

The demand of retailer is

$$
q_{r}=\alpha+\theta_{r}-\lambda p
$$




$$
\theta_{r} \square\left(0, \sigma_{r}^{2}\right)
$$

$\theta_{m}$ and $\theta_{r}$ are irrelevant to $\alpha$, and the $q$ will become more obscure with the growth of $\sigma^{2}$. However, if the market data acquisition and methods of manufacturers and retailers are similar in operation, $\theta_{m}$ and $\theta_{r}$ may be relevant. If exactly the same, $q_{r}$ and $q_{m}$ will be highly correlated, then the covariance is

$$
\Sigma=\left(\begin{array}{cc}
\sigma_{r}^{2} & \eta \sigma_{r} \sigma_{m} \\
\eta \sigma_{r} \sigma_{m} & \sigma_{m}^{2}
\end{array}\right),-1 \leq \eta \leq 1
$$

Assume that covariance is smaller than variance,so

$$
\eta \sigma_{m} \sigma_{r} \leq \sigma_{m}^{2}, \eta \sigma_{m} \sigma_{r} \leq \sigma_{r}^{2}
$$

From(1),(2),(3), $q_{r}$ and $q_{m}$ are two normal distribution. So, we can draw the conclusion that: $\left\{\begin{array}{c}\eta=0 \quad \text { the demand of retailer and manufacturer is not relevant } \\ \eta=1 \quad \text { the demand of retailer and manufacturer is relevant }\end{array}\right.$ In addition to the demand function, the above parameters are information shared by the manufacturer and the retailer. Then other expected requirements can be obtained

$$
\begin{gathered}
\mathrm{E}\left[\theta \mid q_{m}\right]=\frac{\sigma_{0}^{2}}{\sigma_{0}^{2}+\sigma_{m}^{2}} q_{m}-\frac{\sigma_{0}^{2}}{\sigma_{0}^{2}+\sigma_{m}^{2}} \alpha, \operatorname{Var}\left[\theta \mid q_{m}\right]=\left(\frac{\sigma_{0}^{2}}{\sigma_{0}^{2}+\sigma_{m}^{2}}\right)^{2} \sigma_{m}^{2} \\
\mathrm{E}\left[\theta \mid q_{r}\right]=\frac{\sigma_{0}^{2}}{\sigma_{0}^{2}+\sigma_{r}^{2}} q_{r}-\frac{\sigma_{0}^{2}}{\sigma_{0}^{2}+\sigma_{r}^{2}} \alpha, \operatorname{Var}\left[\theta \mid q_{r}\right]=\left(\frac{\sigma_{0}^{2}}{\sigma_{0}^{2}+\sigma_{r}^{2}}\right)^{2} \sigma_{r}^{2} \\
\mathrm{E}\left[\theta \mid q_{m}, q_{r}\right]=\frac{\left(\sigma_{r}^{2}-\eta \sigma_{m} \sigma_{r}\right) \sigma_{0}^{2}}{\left(1-\eta^{2}\right) \sigma_{m}^{2} \sigma_{r}^{2}+\sigma_{0}^{2}\left(\sigma_{m}^{2}+\sigma_{r}^{2}-2 \eta \sigma_{m} \sigma_{r}\right)} q_{r}+\frac{\left(\sigma_{r}^{2}-\eta \sigma_{m} \sigma_{r}\right) \sigma_{0}^{2}}{\left(1-\eta^{2}\right) \sigma_{m}^{2} \sigma_{r}^{2}+\sigma_{0}^{2}\left(\sigma_{m}^{2}+\sigma_{r}^{2}-2 \eta \sigma_{m} \sigma_{r}\right)} q_{m}-\frac{\left(\sigma_{r}^{2}-\eta \sigma_{m} \sigma_{r}\right) \sigma_{0}^{2}}{\left(1-\eta^{2}\right) \sigma_{m}^{2} \sigma_{r}^{2}+\sigma_{0}^{2}\left(\sigma_{m}^{2}+\sigma_{r}^{2}-2 \eta \sigma_{m} \sigma_{r}\right)} \alpha(7) \\
\operatorname{Var}\left[\theta \mid q_{m}, q_{r}\right]=\left(\frac{\left(\sigma_{r}^{2}-\eta \sigma_{m} \sigma_{r}\right) \sigma_{0}^{2}}{\left(1-\eta^{2}\right) \sigma_{m}^{2} \sigma_{r}^{2}+\sigma_{0}^{2}\left(\sigma_{m}^{2}+\sigma_{r}^{2}-2 \eta \sigma_{m} \sigma_{r}\right)}\right)^{2} \sigma_{m}^{2}+\left(\frac{\left(\sigma_{r}^{2}-\eta \sigma_{m} \sigma_{r}\right) \sigma_{0}^{2}}{\left(1-\eta^{2}\right) \sigma_{m}^{2} \sigma_{r}^{2}+\sigma_{0}^{2}\left(\sigma_{m}^{2}+\sigma_{r}^{2}-2 \eta \sigma_{m} \sigma_{r}\right)}\right)^{2}
\end{gathered}
$$

As retailers and suppliers have favorable preferences, they tend to have positive effects on helping the other to increase profits, so the utility function of the supplier and retailer can be expressed as

$$
\begin{aligned}
& U_{m}=\pi_{m}+\beta_{m} \pi_{r} \\
& U_{r}=\pi_{r}+\beta_{r} \pi_{m}
\end{aligned}
$$


Among them, $\pi_{r}$ and $\pi_{m}$ represent the profits of manufacturer and retailer respectively; $\beta_{r}$ and $\beta_{m}$ indicate the coefficient of altruism of manufacturer and retailer respectively $0 \leq \beta_{m} \leq 1,0 \leq \beta_{r} \leq 1$. When $\beta_{r} \approx 1$ and $\beta_{m} \approx 1, U_{r}=U_{m}=\pi_{s}=\frac{1}{2} U_{s}$. At this time, manufacturers and retailers complete altruism, increasing their profits and degree of cooperation in supply chain is very high. Equally important is the distribution of benefits. On the contrary, both sides are fully self-interested, making decisions based on their own maximum profits. This paper focuses on the relationship between the coefficient of altruism in $0 \square 1$.

\section{Model analysis}

This paper assumes that the marginal cost of manufacturers and retailers is 0 , and that the impact of information sharing on market demand is negligible. Then, the corresponding process and model of information sharing behavior as follows

- Manufacturers and retailers decide whether to share information

- Manufacturers set wholesale prices

- Retailers choose sales and sales prices respectively

Above all, manufacturer and retailer can sincerely share information. The profit of manufacture as follow

$$
\begin{aligned}
& \pi_{r}^{0}=(p-\omega)\left(\alpha+\mathrm{E}\left[\theta \mid q_{r}, q_{m}, \omega^{*}\right]-\lambda p\right) \\
& \pi_{m}^{0}=(\omega-c)\left(\alpha+\mathrm{E}\left[\theta \mid q_{r}, q_{m}, \omega^{*}\right]-\lambda \omega\right)
\end{aligned}
$$

The upper approach to the following formula is available

$$
\begin{gathered}
U_{m}=\pi_{m}+\beta_{m} \pi_{r} \\
U_{r}=\pi_{r}+\beta_{r} \pi_{m} \\
\text { So, } U_{m}=(\omega-c)\left(\alpha+\mathrm{E}\left[\theta \mid q_{r}, q_{m}, \omega^{*}\right]-\lambda \omega\right)+\beta_{m}(p-\omega)\left(\alpha+\mathrm{E}\left[\theta \mid q_{r}, q_{m}, \omega^{*}\right]-\lambda p\right) \\
U_{r}=(p-\omega)\left(\alpha+\mathrm{E}\left[\theta \mid q_{r}, q_{m}, \omega^{*}\right]-\lambda p\right)+\beta_{r}(p-\omega)\left(\alpha+\mathrm{E}\left[\theta \mid q_{r}, q_{m}, \omega^{*}\right]-\lambda \omega\right)
\end{gathered}
$$

For retailers, the utility is derived from the upper model,

$$
\frac{d^{2} u_{r}}{d^{2} p}=-2 \lambda<0
$$




$$
\frac{d^{2} u_{m}}{d^{2} \omega}=\lambda\left(\frac{\beta_{m}}{2}-2\right)<0
$$

The existence of unique and optimal solution makes the first derivative equal to 0 .

So,we can draw that

$$
\begin{aligned}
& \frac{d u_{m}}{d \omega}=0 \\
& \frac{d u_{m}}{d \omega}=\left(\alpha+\mathrm{E}\left[\theta \mid q_{r}, q_{m}\right]\right)\left(1-\frac{\beta_{m}}{2}\right)+c \lambda-2 \lambda \omega+\frac{\beta_{m} \lambda \omega}{2} \\
& \omega=\frac{\left(\alpha+\mathrm{E}\left[\theta \mid q_{r}, q_{m}\right]\right)\left(2-\beta_{m}\right)+2 c \lambda}{2 \lambda\left(4-\beta_{m}\right)}
\end{aligned}
$$

Similarly,

$$
\begin{gathered}
\frac{d u_{r}}{d p}=0 \\
\frac{d u_{r}}{d p}=\alpha+\mathrm{E}\left[\theta \mid q_{r}, q_{m}\right]-2 \lambda p+\omega \lambda \\
p=\frac{\alpha+\mathrm{E}\left[\theta \mid q_{r}, q_{m}\right]}{2 \lambda}+\frac{\left(\alpha+\mathrm{E}\left[\theta \mid q_{r}, q_{m}\right]\right)\left(2-\beta_{r}\right)+2 c \lambda}{2 \lambda\left(4-\beta_{r}\right)}
\end{gathered}
$$

Because the $p$ and $\omega$ are derived, the demand is derived from the demand of formula:

$$
\begin{gathered}
q_{r}=\alpha+\theta_{r}-\lambda\left(\frac{\alpha+\mathrm{E}\left[\theta \mid q_{r}, q_{m}\right]}{2 \lambda}+\frac{\left(\alpha+\mathrm{E}\left[\theta \mid q_{r}, q_{m}\right]\right)\left(2-\beta_{r}\right)+2 c \lambda}{2 \lambda\left(4-\beta_{r}\right)}\right) \\
q_{m}=\alpha+\theta_{m}-\lambda\left(\frac{\alpha+\mathrm{E}\left[\theta \mid q_{r}, q_{m}\right]}{2 \lambda}+\frac{\left(\alpha+\mathrm{E}\left[\theta \mid q_{r}, q_{m}\right]\right)\left(2-\beta_{m}\right)+2 c \lambda}{2 \lambda\left(4-\beta_{m}\right)}\right)
\end{gathered}
$$

Bringing $p$ and $\omega$ into the income formula of manufacturers and retailers can be obtained

$$
\begin{aligned}
& \pi_{r}=\frac{1}{\lambda\left(4-\beta_{r}\right)^{2}}\left[\left(\alpha+\mathrm{E}\left[\theta \mid q_{r}, q_{m}\right]\right)-\lambda c\right]^{2} \\
& \pi_{m}=\frac{2\left(2-\beta_{m}\right)}{\lambda\left(4-\beta_{m}\right)^{2}}\left[\left(\alpha+\mathrm{E}\left[\theta \mid q_{r}, q_{m}\right]\right)-\lambda c\right]^{2}
\end{aligned}
$$

Only if the expected profits of manufacturer and retailer were accomplished sharing behave will be occur in the case of information sharing. Therefore, the following constraints are obtained

$$
\left(\alpha+\mathrm{E}\left[\theta \mid q_{m}\right]\right)>\lambda c
$$




$$
\left(\alpha+\mathrm{E}\left[\theta \mid q_{r}, q_{m}\right]\right)>\frac{\left(\alpha+\mathrm{E}\left[\theta \mid q_{r}\right]\right)+\lambda c}{2}
$$

\section{Conclusions}

Manufacturer will sell products to retailer only if they were expected the demand to be large enough and the wholesale price were higher than the marginal cost of the unit. At the same time, retailer will sell products only if the market value of the downstream supply chain was expected to be large enough and the retail price was higher than the wholesale price. Obviously, if the information sharing price level can not meet the expectations of the manufacturer and the retailer, the transaction will not happen, and the profits will be 0 . If

$\alpha>12\left(\sigma_{0}\left(1-\frac{3\left(\sigma_{m}^{2}+\sigma_{r}^{2}-2 \eta \sigma_{m} \sigma_{r}\right) \sigma_{o}^{2}}{4\left(1-\eta^{2}\right) \sigma_{m}^{2} \sigma_{r}^{2}+4 \sigma_{o}^{2}\left(\sigma_{m}^{2}+\sigma_{r}^{2}-2 \eta \sigma_{m} \sigma_{r}\right)}\right)\right)-12\left(\frac{3\left(\sigma_{r}^{2}\left(\sigma_{m}^{2}-\sigma_{m} \sigma_{r}\right) \sigma_{o}^{2}+3 \sigma_{m}\left(\sigma_{m}^{2}-\sigma_{m} \sigma_{r}\right)\right) \sigma_{o}^{2}}{4\left(1-\eta^{2}\right) \sigma_{m}^{2} \sigma_{r}^{2}+4 \sigma_{o}^{2}\left(\sigma_{m}^{2}+\sigma_{r}^{2}-2 \eta \sigma_{m} \sigma_{r}\right)}\right)+\lambda c(25)$

the demand of negative market is probably neglected under the information sharing.

$$
\begin{aligned}
& \frac{d \omega}{d \beta_{m}}<0, \frac{d p}{d \beta_{r}}<0 \\
& \frac{d \pi_{r}}{d \beta_{r}}<0, \frac{d \pi_{m}}{d \beta_{m}}<0
\end{aligned}
$$

From the above, we can draw that the higher level of the altruistic attribute of manufacturer, the more likely the retailer is to make concessions to retailer, and the lower price of wholesale and retail. The higher altruism level of retailer, the higher wholesale price will be accepted by the manufacturer. This paper draw the formula about profits between manufacturers and retailers under altruism coefficient and expected demand, and there is no specific discussion of altruism attribute and expected demand, where the range can reach the whole supply chain maximum profit and the overall supply chain coordination. Next, we can study the specific supply chain equilibrium and the overall revenue maximization through numerical analysis and experimental methods.

\section{References}

1. T. J. Xiao, D. Q. Yang, Price and Service Competition of Supply Chains with Riskaverse.Retailers Under Demand Uncertainty[J]. International Journal of Production Economics, 2008, 114(1):187-200. 
2. A. Y. Ha, S. L. Tong. Contracting and Information Sharing Under Supply Chain.Competition[J].Management Science,2008,54(4):701-715.

3. G. Charness, E. Haruvy, Altruism, equity, and reciprocity in a gift-exchange experiment: an encompassing approach[J]. Games and Economic Behavior, 2002, 40(2): 203-231.

4. M. Rabin. Incorporating fairness into game theory and economics[J]. The American economic review, 1993, 5(83): 1281-1302.

5. V. Pavlov, E. Katok, Fairness and Coordination Failures in Supply ChainContracts[J]. Social Science Electronic Publishing, 2015.

6. Z. Ge, Q. Hu. Who Benefits from Altruism in Supply Chain Management[J]. American Journal of Operations Research, 2012, 2(01): 59.

7. Y. H. Tan, X. Z. Ai, S. Han. Supply chain coordination based on wholesale price contracts under altruistic preferences [J]. industrial engineering and management, 2015, 20 (2): 109-115.

8. M. L. Xu, J. J. Shen, Fairness preference of manufacturer under revenue sharing with the supplier quality management system based on [J]. input journal, 2014, 23 (1): 30.

9. L. Lin. Research on Dual Channel Supply Chain Based on altruistic attributes [J]. China management science, 2014, 22 (12): 126-134.

10. R. Raju, B. P. Pandey, S. Roy, Finite element model of fluid flow inside a microthruster[M]//NanoTech 2002-" At the Edge of Revolution". 2002: 5733. 